\title{
Competência Informacional e Midiática no Ensino de Biblioteconomia: Apontamentos para o Contexto Brasileiro
}

\section{Gabriela Belmont de Farias}

Resumo: Apresenta a contribuição da competência informacional e midiática às ações de ensino aprendizagem que podem influenciar positivamente na formação dos discentes do curso de Biblioteconomia no contexto brasileiro, ao apropriar-se da competência informacional e midiática, colocando-a em prática por meio de intervenções pedagógicas. O objetivo foi proporcionar uma reflexão sobre a competência informacional e midiática na formação do bibliotecário e a todos os contextos de aprendizagem. A pesquisa configura-se por uma abordagem qualitativa de natureza bibliográfica e exploratória. Trata-se de uma contribuição de aspecto inovador e social aos interessados na adoção de novas posturas nesta ambiência de ensino-aprendizagem, além de auxiliar na compreensão das questões fundamentais relacionadas à competência informacional e midiática, possibilitando a sua apropriação junto aos cursos de Biblioteconomia e promovendo o aprofundamento das reflexões ora apontadas e a necessidade de implementá-la como parte da formação básica do bibliotecário.

Palavras-chave: Competência informacional e midiática. Formação Profissional. Biblioteconomia. Ensino.

\section{INTRODUÇÃO}

A sociedade convive em um contexto no qual os avanços das tecnologias da informação e comunicação (TICs) somadas à proliferação das mídias e de outros provedores de informação, veem disponibilizando grandes quantidades de informação que são acessadas e compartilhadas pelos cidadãos. A qualidade da informação que recebemos influencia diretamente e/ou indiretamente nas nossas escolhas e ações. Entretanto o desafio esta em avaliarmos a relevância e a confiabilidade da informação 
sem quaisquer obstáculos em relação aos direitos de acesso à informação e de liberdade de expressão.

O contexto apresentado conduz a uma reflexão sobre o desenvolvimento da competência informacional e midiática no meio universitário, levando em consideração o fato de que é “[...] um processo de aprendizagem, compreendida como ação contínua e prolongada, que ocorre ao longo da vida." (GASQUE, 2012, p.39). A formação profissional de qualidade é um pré-requisito para a inserção da pessoa na sociedade do conhecimento. Para tanto, é necessário refletir sobre novos modelos educacionais que visam à expansão do movimento pela educação cívica que incorpora os professores como os principais agentes de mudança.

No entendimento de Jesus Lau (2007, p.4) “[...] as habilidades em informação são fatores chave na aprendizagem ao longo da vida e o primeiro passo na consecução das metas educacionais de qualquer aprendiz". Corroborando a ideia de que a Competência em Informação deve ser um elemento inserido nas políticas públicas brasileiras, Belluzzo (2013) reafirma esta noção, ao descrever que a Competência em Informação é uma condição sine qua non ao desenvolvimento e inovação social de um país. A competência em informação somada à habilidade midiática incorpora conhecimentos essenciais sobre:

(a) as funções da mídia, das bibliotecas, dos arquivos e de outros provedores de informação em sociedades democráticas; (b) as condições sob as quais as mídias de notícias e os provedores de informação podem cumprir efetivamente essas funções; e (c) como avaliar o desempenho dessas funções pela avaliação dos conteúdos e dos serviços que são oferecidos. (WILSON et al, p.16, 2013).

Esses conhecimentos, por sua vez, podem permitir que os futuros bibliotecários se engajassem junto às mídias e aos canais de informação de uma maneira significativa. As competências adquiridas pela competência informacional e midiática podem permitir ao futuro bibliotecário habilidades de raciocínio crítico, permitindo que eles demandem 
serviços de alta qualidade das mídias e de outros provedores de informação, fomentando um ambiente propício em que as mídias e outros provedores de informação possam prestar serviços de qualidade.

O objetivo deste artigo é sinalizar a necessidade de sensibilização quanto à aplicabilidade da competência informacional e midiática no ensino superior e de planejar atividades de orientação para a aquisição dessas competências.

O recorte neste artigo tem como foco o ensino de Biblioteconomia, pois, segundo as Diretrizes Curriculares (BRASIL, 2001), os cursos de Biblioteconomia têm a missão de formar bibliotecários competentes, proficientes e criativos para solucionar as demandas de sua prática profissional, o que não significa, porém, que as noções aqui estabelecidas não possam ser redirecionadas para outra área do conhecimento.

\section{COMPETÊNCIA INFORMACIONAL E MIDIÁTICA}

A fim de ajudar no entendimento e na elaboração de uma consciência pública da competência informacional e midiática, com vistas a solucionar os problemas relacionados à "explosão informacional" por meio das mídias e outros provedores de informação. Os bibliotecários podem atuar em bibliotecas, arquivos e internet, como mediadores amplamente reconhecidos por auxiliarem os cidadãos a tomarem decisões bem informadas.

Os estudos sobre competência informacional e midiática no Brasil têm como precursores os pesquisadores da área da Ciência da Informação e bibliotecários que iniciaram as pesquisas no ano 2000, tendo como objeto a competência em informação (CoInfo). Assim, desde 2000, o movimento pela concretização da CoInfo vem se tornando cada vez mais forte, em virtude das várias manifestações públicas realizadas, como: os eventos organizados pela IFLA e outras organizações profissionais, várias declarações publicadas por diversos países, sobre CoInfo, entre outras. No Brasil, o movimento pela 
consolidação da CoInfo somada às habilidades midiáticas está sendo realizado mediante o desenvolvimento de atividades com o propósito de informar e formar profissionais conscientes da aplicabilidade da competência informacional e midiática em suas atividades biblioteconômicas, acadêmicas e social.

Com base nesses elementos é necessário estabelecer os conceitos entre CoInfo e competência midiática. Para Wilson et al (2013), a CoInfo está relacionada à habilidade de reconhecer quando as informações são necessárias e como localizar, avaliar, utilizar de forma eficaz e comunicar informações em seus diversos formatos. Já a competência midiática está pautada na compreensão e o uso das mídias de massa de maneira incisiva ou não, incluindo um entendimento bem informado e crítico das mídias, das técnicas que elas empregam e dos seus efeitos. Incluindo a capacidade de ler, analisar, avaliar e produzir a comunicação em uma série de formatos de mídias.

Evidencia-se, nestas definições, a necessidade da pessoa aprender a produzir um conhecimento desde o procedimento inicial, qual seja a, busca, permeia o acesso e termina no uso eficiente da informação, seja aplicada a uma necessidade específica, para a resolução de problemas e tomada de decisão, seja buscando o aprendizado contínuo, desenvolvendo competências que objetivem conhecer e usufruir do complexo ambiente informacional.

Percebe-se, por intermédio da leitura e sistematização de diversos textos publicados sobre o assunto, que o núcleo do desenvolvimento da competência informacional e midiática é o processo cognitivo para a resolução de problemas por via do pensamento crítico e criativo.

O desenvolvimento da competência informacional e midiática tem como pontos fundamentais a alfabetização e, o letramento que, segundo Gasque (2012), são conceitos inter-relacionados hierarquicamente, além do contexto sociocultural. Estes elementos subsidiam o desenvolvimento da pessoa no que diz respeito à busca e uso da informação, ou seja, aquele com deficiência em um desses elementos citados, provavelmente, terá níveis de desenvolvimentos de habilidades informacionais abaixo da média em relação 
ao que possui excelência nos três elementos. A adaptação e a socialização dos indivíduos na sociedade só se tornam efetivos quando o mesmo possui a capacidade de:

Determinar a extensão das informações necessárias; acessar a informação de forma efetiva e eficientemente; avaliar criticamente a informação e suas fontes; incorporar a nova informação ao conhecimento prévio; usar a informação de forma efetiva para atingir objetivos específicos; compreender os aspectos econômico, legal e social do uso da informação, bem como acessá-la e usá-la ética e legalmente (GASQUE, 2012, p. 31-32).

Observa-se que aquele capaz de atender à demanda dessa sociedade complexa necessita compreender a informação desejada no contexto no qual está inserido, para que na sua busca haja um pensamento crítico, a fim de poder avaliar, selecionar e incorporar fontes de informações que venham a atender, especificamente, as necessidades expressas e que, ao fazer o uso da informação, é primordial que compreenda os aspectos econômicos, legais e sociais, bem como a forma ética de uso da informação, tendo como finalidade a resolução de problemas e a realização de atividades específicas e circunscritas, visando atingir diretrizes que possam ser norteadoras de uma sociedade sustentável.

Na compreensão de Belluzzo (2013), para que se possa estabelecer a competência informacional e midiática sustentável, é necessário compreender três requisitos fundamentais: a cidadania - reporta-se ao uso crítico de dados e informação; o crescimento econômico - refere-se ao uso criativo e intensivo do conhecimento e à combinação eficiente dos serviços de informação; e a empregabilidade, relacionada ao desenvolvimento contínuo da pessoa com estratégias necessárias para o acesso e o êxito econômico. É necessário refletir sobre os requisitos principais para o desenvolvimento da competência informacional e midiática no contexto brasileiro:

a) Existência de espaços de intercâmbio e participação por meio do fomento de práticas pedagógicas e informacionais, tendo como base a filosofia da educação para todos. 
b) Estabelecimento de estreita relação entre as bibliotecas e as escolas, mediante trabalho integrado e conjunto, com o intuito de promover a leitura e a pesquisa.

c) Garantia do acesso e uso da informação de forma inteligente para a geração de conhecimento às comunidades assistidas e populações vulneráveis.

d) Atualização de princípios e práticas de condutas de gestão da informação àqueles que atuam como mediadores e multiplicadores no desenvolvimento da Competência em Informação, contribuindo com a inovação e o desenvolvimento social (BELLUZZO, 2013, p.77).

A complexidade de estabelecer uma conexão da filosofia da competência informacional e midiática e os ambientes educacionais e corporativos é desafiadora, pois a compreensão dessa filosofia, muitas vezes, é limitada, prejudicando o desenvolvimento de programas educacionais ou de capacitação. Na sequência, demonstrar-se-á de que maneira a competência informacional e midiática está sendo tratada no ensino de Biblioteconomia.

\section{ENSINO SUPERIOR: A COMPETÊNCIA INFORMACIONAL E MIDIÁTICA}

A universidade é uma instituição social inseparável da ideia de democracia e de democratização do saber, sendo que, no decorrer da mencionada centúria a instituição universitária não pôde furtar-se à referência à democracia como uma ideia reguladora. A universidade é uma instituição social, isto é, uma ação social, uma prática social fundada no reconhecimento público de sua legitimidade e de suas atribuições, num princípio de diferenciação, que lhe confere autonomia perante outras instituições sociais, e estruturadas por ordenamentos, regras, normas e valores de reconhecimento e legitimidade internos a ela (CHAUI, 2003).

Observa-se que o ensino superior tem como primícias para seu funcionamento o tripé do ensino-pesquisa-extensão, tendo um papel fundamental para a sociedade, pois reúne "[...] um conjunto de funções associadas ao progresso e a transmissão do saber: pesquisa, inovação, ensino e formação, educação permanente” (DELORS, 1998, p.141). 
O ensino superior deve considerar as variadas condições de desenvolvimento e inovação da atual sociedade complexa, migrando de uma profissão tradicional de transmissora de informação e de cultura para um comportamento de ensinar a aprender e a pensar, preparando pessoas capazes de aplicar os conhecimentos, facilitando o uso da inteligência na vida profissional e no cotidiano social.

A missão do ensino superior para o Século XXI, segundo a Declaração Mundial sobre o Ensino Superior da Organização das Nações Unidas para a Educação, a Ciência e a Cultura -(UNESCO), abrange os seguintes aspectos:

a) formar profissionais altamente qualificados e cidadãos responsáveis, capazes de atender às necessidades de todos os aspectos da atividade humana;

b) constituir um espaço aberto que propicie a aprendizagem permanente;

c) promover, gerar e difundir conhecimentos por meio da investigação e proporcionar as competências técnicas adequadas para o desenvolvimento cultural, social e econômico das sociedades;

d) compreender, interpretar, preservar, reforçar, fomentar e difundir as culturas nacionais e regionais, internacionais $\mathrm{e}$ históricas, em um contexto de pluralismo e diversidade cultural;

e) consolidar os valores da sociedade, mostrar aos jovens o valor da cidadania e proporcionar perspectivas críticas e objetivas, a fim de propiciar o debate sobre as opções estratégicas e o fortalecimento de enfoques humanistas (UNESCO, 1998)

Se o ensino superior tem a função de formar pessoas críticas e reflexivas que contribuam para o desenvolvimento econômico e social, a competência informacional e midiática se faz elemento indissociável do ensino, pois permitirá ao aluno o desenvolvimento de habilidades críticas, criativas e reflexivas. Takahashi (2000, p.45) corrobora e amplia essa concepção, ao acentuar que a função do ensino superior é 
[...] muito mais que treinar pessoas para o uso de tecnologias de informação e comunicação: trata-se de investir na criação de competências suficientemente amplas que lhes permitam ter uma atuação efetiva na produção de bens e serviços, tomar decisões fundamentadas no conhecimento, operar com fluência os novos meios e ferramentas em seu trabalho, bem como aplicar criativamente as novas mídias, seja em usos simples e rotineiros, seja em aplicações mais sofisticadas. Trata-se também de formar indivíduos para 'aprender a aprender', de modo a serem capazes de lidar positivamente com a contínua e acelerada transformação da base tecnológica.

Ante o exposto, percebe-se que o ensino superior precisa passar por profundas transformações em suas práticas e culturas para enfrentar os desafios do mundo contemporâneo.

Com efeito, destaca-se a necessidade de refletir sobre como institucionalizar uma política de formação de competência informacional e midiática no âmbito do ensino superior, de forma integrada a prática de ensino-aprendizagem, que busque uma

[...] estratégia didática estruturante, que permite, ao aluno, realizar suas tarefas cotidianas, mas que transcende à sala de aula e ao período acadêmico, pois alicerça as bases da educação permanente e da competência profissional e ao longo da vida. $\mathrm{O}$ trabalho tem maior possibilidade de êxito pleno, quando professores e docentes assumem a causa, de modo coeso, comungando dos mesmos ideais e atuando cooperativamente, e quando há uma conjugação de esforços assumida pelas autoridades acadêmicas e administrativas da universidade, que atuam dando os subsídios políticos, pedagógicos e de infraestrutura. (VARELA; BARBOSA; FARIAS, 2013, p.203).

Uribe-Tirado (2010) em suas pesquisas categorizou as universidades conforme os graus de incorporação da filosofia CoInfo. Essas categorizações estão divididas em quatro níveis, sendo eles: nível 1 - universidades comprometidas oferecem ações instrumentais 
somadas a aprendizagem ao longo da vida mais pensamento crítico. As ações são oficiais e estão inseridas no currículo dos cursos de graduação além da competência ser desenvolvida de forma transversal e como disciplina. Nível 2 - universidades em crescimento oferecem ações instrumentais somadas a aprendizagem ao longo da vida mais pensamento crítico. Nível 3 - universidades iniciando oferecem ações básicas direcionadas a recuperação de informação e uso de base de dados. Nível 4 - universidades desconhecedoras não oferecem ações que estimula o desenvolvimento de habilidades informacionais.

No contexto universitário, a análise, o discurso e a assimilação da informação ensejam conhecimento, que poderá contribuir para o desenvolvimento da sociedade. Para tanto, é necessário que ele seja divulgado para que esse processo ocorra em todas as atividades acadêmicas, é primordial a competência intelectual, ligada à cognição, somada à competência informacional e midiática, que permite seleção e o gerenciamento de informações em curso. Ressalta-se que:

Esta postulação da perícia humana como crucial para gerir e lidar com informações ainda se mantém no século 21, e é um elemento chave nas percepções conflitantes da Competência em Informação dentro do ambiente de ensino superior (COONAN, 2011, p.7).

A competência informacional e midiática parece ser um elemento fundamental da prática universitária, pois ela se manifesta na compreensão específica da criação de conhecimento, a atividade acadêmica, e processos de ensino-aprendizagem das disciplinas. O meio acadêmico, entretanto, ao mesmo tempo em que se mostra favorável à ideia de aumentar as habilidades relacionadas à competência informacional e midiática dos alunos, reluta em incorporar a filosofia na grade curricular, em especial, dos cursos de Biblioteconomia. Se, houver, a informação de alto nível de manipulação é crucial para a missão acadêmica, e se a competência informacional e midiática é fundamental para a 
aprendizagem em todos os contextos, por que não inseri-la como um elemento significativo no currículo acadêmico?

Anteriormente, Stubbings e Franklin (2006) já indicavam haver uma série de razões para que a competência informacional e midiática não estivesse inserida nos currículos acadêmicos: a falta de compreensão por parte dos professores, a confusão com o conceito da Competência em Informação com competência em tecnologia da informação (TI), e os equívocos dos estudantes que se acreditam competentes em informação por saberem pesquisar na Internet.

No tocante à confusão entre o conceito da Competência em Informação e o da competência de TI, a ACRL (2000) reconhece que as habilidades de TI são entrelaçadas com a Competência em Informação, mas que a competência informacional e midiática tem implicações mais amplas para a pessoa, o sistema educacional e para a sociedade.

Badke (2010) vai mais longe, ao acentuar que a Competência em Informação é um elemento "invisível" dentro da universidade, por uma série de causas:

Porque ele é mal compreendida, os gestores acadêmicos não a insere nas agendas das suas instituições, o embasamento teórico da literatura sobre a Competência em Informação permanece exclusivamente com os bibliotecários, há uma falsa crença de que a competência em informação é adquirida apenas pela experiência, há uma falsa suposição de que a capacidade tecnológica é o mesmo que competência em informação, a cultura do corpo docente faz co que a competência em informação seja menos importante do que as outras atividades de educação, professores têm uma percepção limitada da competência em informação e os organismos de acreditação não tem ainda informações avançadas sobre a competência em informação para uma posição viável no ensino superior (BADKE, 2010, p.129).

Observa-se a falta de entendimento no contexto universitário sobre a Competência em Informação, que pode ser atribuída, segundo Coonan (2011), a um conflito de 
percepção em torno da natureza da informação e como lidar com isso. Este conflito levou a uma separação dos aspectos funcionais e intelectuais do termo "informação"; e, nesse conflito conceitual, a Competência em Informação se fez reducionista e alinhada com habilidades de nível operacional e relacionada às atividades funcionais ou básicas.

Separar os aspectos funcionais de lidar com a informação em seu contexto e práticas disciplinares pode suscitar uma não contextualização da competência informacional e midiática, o que pode ser visto como complementar às práticas acadêmicas, em vez de uma parte determinante da missão acadêmica. Levando a competência informacional e midiática como área de apoio, dessa maneira, poderá alcançar um grau de notoriedade e visibilidade, atraindo apoio institucional e recursos; no entanto, isso também suscita uma percepção da competência informacional e midiática como opcional ou complementar, em vez de um elemento fundamental da teoria e da prática universitária. No ensino superior, a competência informacional e midiática não é um tema secundário, mas todo um modo de pensar sobre a informação e seu uso.

A competência informacional e midiática é tão complexa, sofisticada e entrelaçada com a forma como se usa a informação - todos os dias, bem como academicamente - que se deve demandar esforços para percebê-la

[...] como indivisível dos processos que constituem a pesquisa em seu contexto mais amplo: os processos de avaliação, comparação e seleção; de questionamento e problema de enquadramento; de sintetizar visualizações variante e criar novos. Assim, há uma necessidade imperiosa de reabilitar a percepção da Competência em Informação e reconhecer que não é apenas um conjunto de habilidades e competências, mas um contínuo que começa com habilidades e competências e sobe em direção de alto nível de comportamentos e abordagens intelectuais e metacognitivas (COONAN, 2011, p.20).

A fim de estabelecer verdadeiramente uma abordagem da competência informacional e midiática que apoia os alunos em cada etapa da graduação, é necessária 
maior conscientização e impõe-se mais reflexão sobre os métodos de ensino, estilos e práticas por parte dos professores; mas há uma necessidade paralela de apoio institucional para os membros da equipe educacional (professores, bibliotecários) que vai aplicar a competência informacional e midiática no ensino como algo continuo de aprendizagem e desenvolvimento. Até que isso ocorra, é possível que haja percepção de a competência informacional e midiática ser uma filosofia de mudança de hábitos de aprendizagem de forma permanente que permita aos alunos trafegar em labirinto desigual da sociedade da informação e vê-lo com a característica definidora do estudioso exigente, o cidadão informado e criterioso, e o aprendiz autônomo. Todos são dotados da capacidade de tomar uma posição de modo individual, para expressar opiniões, e constituir identidade, “[...] mas para que a nossa contribuição para a sociedade seja significativa e valiosa, deve ser enraizada e guiada por uma visão de mundo da filosofia da Competência em Informação" (COONAN, 2011, p.23).

A perspectiva de integração da competência informacional e midiática ao currículo universitário requer uma compreensão, da parte dos gestores, bibliotecários e docentes, de que a CoInfo enfatiza a importância do acesso à informação e a avaliação do uso ético dessa informação. Por outro, a competência midiática enfatiza a capacidade de compreender as funções da mídia, de avaliar como essas funções são desempenhadas e de engajar-se racionalmente junto às mídias com vistas à autoexpressão.

Os argumentos e razões ora expostos explicam a necessidade de incorporar a competência informacional e midiática ao ensino superior. Relativamente à formação biblioteconômica, Mata e Casarin (2012), após realizarem um levantamento nos sites de instituições universitárias brasileiras para identificar a existência de disciplinas de Competência em Informação e de formação pedagógica na formação do bibliotecário, evidenciaram que a necessidade da formação, do futuro profissional está alicerçada nos preceitos da competência informacional e midiática e com bases pedagógicas, já que este profissional atuará como mediadores. Portanto a ideia de que a competência informacional e midiática pode ser inserida como um componente curricular por meio de disciplinas específicas ou já existentes, por meio da pesquisa, ou, ainda, por práticas 
pedagógicas com os alunos de biblioteconomia. Não será demais lembrar, entretanto, que a abordagem da competência informacional e midiática deve perpassar todas as disciplinas, pois ela é um conteúdo transversal.

O princípio do ensino-aprendizagem da competência informacional e midiática está relacionado à prática como norteadora pedagógica central, em que estão fundamentadas as ópticas social, cultural e psicológica que possibilitem aos alunos serem independentes e produtivos no âmbito informacional. Nesta concepção, pode-se entender que a finalidade da prática pedagógica é de proporcionar experiências de ação didática e convergir entre a ação pedagógica e a competência informacional e midiática. "Desenvolver projetos pedagógicos voltados para a Competência em Informação significa repensar crenças, práticas e partir para a ação" (DUDZIAK, 2005, p.3-4). Caso contrário, haverá uma desvalorização do entendimento de sua aplicação, pois, na intelecção de Santos (2013), a ausência de fundamentação crítica e reflexiva sobre o desenvolvimento da competência informacional e midiática compromete a possibilidade de desenvolver alunos com atitudes e valores perante o universo informacional.

A deliberação por uma determinada teoria da aprendizagem ou pelo somatório de teorias para o embasamento de uma proposta educacional de desenvolvimento da competência informacional e midiática torna-se relevante para definir o roteiro mediante o qual será incrementado o fundamento de um modelo pedagógico de desenvolvimento da Competência em Informação.

É necessário que a comunidade universitária (gestores, docentes, bibliotecários, técnicos e estudantes) esteja mobilizada para desenvolver uma política de competência informacional e midiática e integrá-la ao currículo, visto que, no Brasil, essa competência não se encontra institucionalizada, ao contrário de outros países, como os Estados Unidos, Canadá e Espanha entre outros.

Os desafios de se implementar uma ação efetiva no ambiente universitário são complexos, pois, existem variáveis que precisam ser analisadas com cautela. Uma delas -aponta Cavalcante (2006) - está nas deficiências e lacunas que os alunos que entram e 
saem de um curso superior têm em relação à Competência em Informação. Essa ausência contribui para "[...] o abandono ou trancamento, número de anos no curso além da média, dificuldade de integração, descontentamento com a área que escolheu ou falta de oportunidade no mercado de trabalho" (CAVALCANTE, 2006, p.52).

Ao pensar em ações de ensino-aprendizagem da competência informacional e midiática, é preciso partir da constituição de um compromisso no âmbito institucional para que as ações tenham êxito. As ações devem estar pautadas em uma concepção globalizada e ser efetivadas, por meio de projetos e procedimentos de aprendizagem sistemáticos. A competência informacional e midiática exige nova concepção de aprendizagem e de atitude pedagógica da parte dos educadores e do próprio projeto pedagógico dos cursos. Os desafios a serem superados ao implementar a competência informacional e midiática no ambiente educacional: dificuldade em mudar a cultura pedagógica, formação inadequada dos professores, concepção de ensino-aprendizagem, organização do currículo e ausência de infraestrutura adequada de informação. (GASQUE, 2012, p.151-152).

Tais dificuldades conduzem a reflexão sobre o papel das instituições educacionais na sociedade, surgindo questionamentos que envolvem analisar se realmente elas possibilitam um espaço dinâmico no qual as pessoas desenvolvem a capacidade de pensar criticamente, de exprimir autonomia por intermédio da transdicisplinaridade oferecida no currículo e pelas experiências vivenciadas no meio acadêmico. Além desses desafios, outros aspectos devem ser levados em conta, tais como:

a. Estabelecer uma infraestrutura básica de telecomunicações e redes de computadores, de modo a tornar acessíveis, através da tecnologia, as informações relativas à comunidade educacional, bem como garantir o acesso a dados, fatos, acontecimentos e conhecimentos que envolvem a comunidade e o mundo.

b. Facilitar a integração da informação ao currículo, criando uma cultura de uso da biblioteca; isto implica necessariamente na valorização da biblioteca enquanto sistema multicultural e pluralístico. 
c. Oferecer todas as oportunidades para que a comunidade educacional se aproprie da tecnologia e dos recursos informacionais em seus variados formatos, de modo que se crie um ambiente educacional favorável à pesquisa, à investigação, enquanto processo de busca e uso de informações para a construção de conhecimento e tomadas de decisão conscientes.

d. Fomentar o diálogo entre todos os membros da comunidade educacional.

e. Buscar parcerias, o trabalho cooperativo, transdisciplinar, integrado.

f. O bibliotecário deve adquirir uma postura ativa, dialogando com os docentes, buscando novas atividades e práticas pedagógicas que potencializem os processos de aprendizado a partir da busca e uso da informação, a investigação, o pensamento crítico, incentivando o aprendizado independente, auto-orientado dos estudantes.

g. Enquanto espaço, a Biblioteca deve ser o tanto quanto possível um ambiente propício ao estudo, à descoberta, autoexplicativa, proporcionando as condições ideais à investigação e o aprendizado. Os bibliotecários que nela atuam devem incentivar o diálogo interno e externo com a comunidade acadêmica, tornando-a uma organização aprendente (DUDZIAK, 2002a, p.8-9).

O desenvolvimento de ações de competência informacional e midiática na perspectiva do ensino superior pode ser definido, por meio de uma política de formação em que competência informacional e midiática poderá ter como base de sua elaboração os elementos da competência informacional e midiática elaborado por Wilson et al (2013), conforme a imagem abaixo. 
Figura 1: Resultados e elementos da alfabetização midiática e informacional ${ }^{4}$

Alfabetização informacional

\begin{tabular}{l|l|l|l|l|l|l}
$\begin{array}{l}\text { Definiçáo e } \\
\text { articulaçăo de } \\
\text { necessidades } \\
\text { informacionais }\end{array}$ & $\begin{array}{l}\text { Localizaçăo e } \\
\text { acesso à infor- } \\
\text { maçăo }\end{array}$ & $\begin{array}{l}\text { Acesso à infor- } \\
\text { maçáo }\end{array}$ & $\begin{array}{l}\text { Organizaçăo da } \\
\text { informaçăo }\end{array}$ & $\begin{array}{l}\text { Uso ético da } \\
\text { informaçăo }\end{array}$ & $\begin{array}{l}\text { Comunicaçăo } \\
\text { da informaçáo }\end{array}$ & $\begin{array}{l}\text { Uso das habili- } \\
\text { dades deTICs no } \\
\text { processamento } \\
\text { da informaçăo }\end{array}$ \\
\hline
\end{tabular}

Alfabetização midiática ${ }^{5}$

\begin{tabular}{|c|c|c|c|c|}
\hline $\begin{array}{l}\text { Compreensáo do papel } \\
\text { e das funçōes das } \\
\text { mídias em sociedades } \\
\text { democráticas }\end{array}$ & $\begin{array}{l}\text { Compreensáo das con- } \\
\text { diçōes sob as quais as } \\
\text { mídias podem cumprir } \\
\text { suas funçőes }\end{array}$ & $\begin{array}{l}\text { Avaliaçăo crítica do } \\
\text { conteúdo midiático } \\
\text { à luz das funçōes da } \\
\text { mídia }\end{array}$ & $\begin{array}{l}\text { Compromisso junto às } \\
\text { mídias para a autoex- } \\
\text { pressăo e a participa- } \\
\text { çăo democrática }\end{array}$ & $\begin{array}{l}\text { Revisáo das habilida- } \\
\text { des (incluindo as TICs) } \\
\text { necessárias para a } \\
\text { produçáo de conteú- } \\
\text { dos pelos usuários }\end{array}$ \\
\hline
\end{tabular}

Fonte: Wilson et al, 2013, p.18

As ações de aprendizagem para o ensino superior pressupõem que o ato de reflexão seja a base para as ações vinculadas ao desenvolvimento da competência informacional e midiática, pois, ao estimular a capacidade de compreender o objeto pela investigação e sistemática metodológica da relação do objeto com o fenômeno, a pessoa refletir sobre suas ações. Na óptica de Gasque (2012, p. 57):

O pensamento reflexivo é utilizado como estratégia cognitiva na construção das competências necessárias à busca e ao uso da informação, possibilitando a compreensão mais profunda das questões, fenômenos e processos envolvidos por meio da percepção das relações, da identificação dos elementos, da análise e interpretação dos sentidos e significados.

O pensamento reflexivo possibilita aos discentes constituir e modificar ideias e comportamentos, entre outros elementos, fazendo-se necessário levar em consideração as experiências e conhecimentos, adquiridos durante a vida, além de atitudes, como espírito aberto, responsabilidade e envolvimento, pois esses elementos é que possibilitarão o desenvolvimento da competência informacional e midiática, compreendendo um 
conjunto de habilidades adequadas durante sua passagem pelas disciplinas cursadas no ensino superior, bem como, posteriormente, no mercado de trabalho. É importante aqui proporcionar um ambiente mais participativo e democrático.

O pensamento reflexivo sugere uma natureza pré-reflexiva, problemática no início, e uma situação pós-reflexiva, de esclarecimento e de resolução no fim. Entre esses limites, situam-se cinco fases que não elucidam sequência fixa e podem ser ampliadas para incluir sub fases:

a. sugestões: ideias que surgem da observação ou lembranças evocadas, em que se definem planos e estratégias para uma possível solução;

b. intelectualização: formulação da pergunta, visando a situar com exatidão o problema;

c. ideia-guia ou hipótese: sugestões que orientam as observações e operações na coleta de dados;

d. raciocínio: elaboração mental da ideia que fornece termos intermediários conectados aos elementos de forma consistente;

e. verificação da hipótese: realizada mediante provas, caso os resultados correspondam aos que foram deduzidos teórica ou racionalmente e se somente as condições em questão forneceriam tais resultados. Nesses casos, a confirmação é tão forte que induz a uma conclusão até que novos fatos indiquem outra revisão (GASQUE, 2012, p.63).

Os períodos mencionados fazem refletir a ideia de que o pensamento é constituído por meio da reflexão dos conteúdos lecionados em sala de aula, como também das conexões efetivadas com outros conhecimentos, “[...] criando condições para revisar os conhecimentos anteriores e despertar o espírito do aprendiz para seguir avante" (GASQUE, 2012, p.67). ${ }^{1}$

\footnotetext{
1 Observa-se que Gasque (2012) baseia-se no pensamento Deweyano, no qual os programas de Competência em Informação devem ter como ênfase o relacionamento entre experiência, reflexão crítica e aprendizagem.
} 
Após estas considerações e reflexões, buscar-se-á estabelecer as possíveis contribuições da competência informacional e midiática na formação de futuros bibliotecários.

\section{CONTRIBUIÇÃO DA COMPETÊNCIA INFORMACIONAL E MIDIÁTICA PARA O ENSINO DE BIBLIOTECONOMIA}

A competência informacional e midiática segundo Wilson et al (2013) vai além daquilo que as terminologias significam individualmente, alcançando uma noção unificada que incorpora elementos tanto da competência midiática quanto da CoInfo. $\mathrm{Na}$ obra "Alfabetização midiática e informacional: currículo para formação de professores" o Wilson et al, apresenta três principais benefícios da competência informacional e midiática, que aqui iremos dimensionar para o ensino de Biblioteconomia, estão expressos a seguir: no processo de ensino e aprendizagem, os futuros bibliotecários terão um conhecimento aprimorado em relação ao uso do meio de comunicação midiática capazes de contribuir com o empoderamento dos cidadãos, além de transmite conhecimentos cruciais sobre as funções das mídias e dos canais de informação nas sociedades democráticas. Bem como habilidades para avaliar o desempenho das mídias e dos provedores de informação à luz das funções esperadas. E por fim promover o desenvolvimento de mídias livres, independentes e pluralistas, e de sistemas abertos de informação.

Para tanto é necessário que a competência informacional e midiática deva ser considerada como um todo e deve incluir uma combinação de competências (conhecimentos, habilidades e atitudes). O currículo deve prover conteúdos teóricos práticos essenciais para que haja engajamento junto às mídias e aos canais de informação a fim de ter conhecimentos sobre a localização e o consumo de informações, bem como sobre a produção de informações e que essa produção de informação e conhecimento seja acessada de maneira igualitária às mulheres, homens e a grupos marginalizados, como as pessoas com deficiências, os povos indígenas ou as minorias étnicas. Pois a competência 
informacional e midiática deve ser vista como uma ferramenta essencial para facilitar o diálogo intercultural, a compreensão mútua e a compreensão cultural entre os povos. (WILSON et al, 2013).

Com base do conteúdo exposto é necessário alinharmos a estrutura curricular dos cursos de Biblioteconomia, as recomendações do grupo de especialistas da UNESCO sobre competência informacional e midiática, em consonância com as três áreas temáticas centrais e inter-relacionadas. São elas:

$1^{a}$ Área temática - o conhecimento e a compreensão das mídias e da informação para os discursos democráticos e para a participação social.

O objetivo desta área temática é desenvolver a compreensão crítica de como as mídias e a informação podem aprimorar a capacidade dos discentes de biblioteconomia engajarem-se às mídias e usarem os recursos disponíveis nas bibliotecas, arquivos e outros provedores de informação como ferramentas para a liberdade de expressão, o pluralismo, o diálogo e a tolerância intercultural que contribuam para o debate democrático e a boa governança.

$2^{\mathbf{a}}$ Área temática - a avaliação dos textos de mídia e das fontes de informação.

O objetivo é aumentar a capacidade do pensamento critico, dos discentes de biblioteconomia para avaliar as fontes e acessar informações a partir de funções específicas do serviço público, normalmente atribuídas à mídia, às bibliotecas, aos arquivos e a outros provedores de informação. Além de propiciar o conhecimento das ações que podem ser realizadas quando esses sistemas desviam-se de seus papéis esperados. Os futuros bibliotecários devem estar em condições de analisar e entender como o conteúdo das mídias e outras informações são produzidos, como as informações apresentadas por esses sistemas podem ser avaliadas e como as mídias e a informação podem ser usadas para diferentes propósitos. Os discentes de biblioteconomia devem estar em condições de explorar a questão da representação em diversos sistemas de mídia e em relação às TICs, bem como as maneiras como a diversidade e a pluralidade são 
abordadas tanto nas mídias locais quanto nas globais. Por fim, discentes de biblioteconomia devem desenvolver a capacidade de avaliar como os usuários interpretam as mensagens de mídia e as informações de uma série de fontes.

$3^{\mathbf{a}}$ Área temática - a produção e o uso das mídias e da informação.

Os discentes de biblioteconomia devem desenvolver as competências necessárias para que eles engajem-se junto às mídias e às plataformas de informação, para que possam comunicar-se de maneira significativa e alcançar a autoexpressão. Isso envolve o conhecimento de ética nas mídias e infoética com base nos padrões internacionais, incluindo o campo das competências interculturais. Além disso, os discentes devem desenvolver habilidades que lhe permita auxiliarem os usuários na aplicação dessas ferramentas e fontes em sua aprendizagem, especialmente em relação à busca de informação e à produção de conteúdo.

À medida que os discentes de biblioteconomia desenvolvem competências e tornam-se confiantes para produzir e usar mídias e informações para práticas instrutivas, eles passam a serem líderes na promoção da competência informacional e midiática. $\mathrm{O}$ ponto de partida deve ser a compreensão das políticas nacionais de educação, permitindo as leis sobre liberdade de expressão e liberdade de informação, além de outros instrumentos internacionais relacionados às liberdades e suas intersecções com as políticas de competência informacional e midiática.

Por fim, ela deve chamar atenção para o papel dos bibliotecários na promoção de cidadãos competentes em informação e em mídia.

\section{CONCLUSÃO}

Foram delineados e discutidos diversos conceitos para o entendimento da competência informacional e midiática no ensino-aprendizado. Com amparo numa visão integradora entre essas temáticas, foi possível verificar a possibilidade de 
desenvolvimento de práticas pedagógicas com base na competência informacional e midiática, durante a formação básica do bibliotecário.

Evidencia-se que o processo de ensino-aprendizagem na contemporaneidade não está relacionado apenas à dimensão subjetiva dos sujeitos envolvidos, indo além das habilidades cognitivas. É necessário refletir, entretanto, questionar e redefinir os papéis dos sujeitos na educação, para que o docente, na qualidade de mediador desse processo, possa analisar sua práxis pedagógica, constituindo mais possibilidades de aprendizagem com a origem na necessidade da realidade na qual o aluno está inserido, mas com o foco na realidade e demanda da sociedade.

Os protagonistas, docentes e alunos, da sala de aula precisam refletir e agir de forma colaborativa para as mudanças educacionais emergentes da sociedade contemporânea. Portanto, são necessários múltiplos papéis e funções do docente, além de promover ações que potencializem a criatividade dos alunos. Este é o grande desafio para os educadores, em especial aos docentes da área da Ciência da Informação, pois, constantemente, a sociedade atribui e exige novas competências ao profissional bibliotecário. Para isso, há necessidade de selecionar estratégias pedagógicas que possibilitem o desenvolvimento da criatividade e da competência informacional e midiática.

A transposição desse cenário para a formação do bibliotecário, reside no fato de que ela não está somente focada em conhecimentos técnicos e teóricos, razão do porque não garante a efetividade de sua atuação no mercado de trabalho, sendo necessário impulsionar a existência de mudanças significativas na sua formação, para que estes profissionais tenham conhecimentos e atitudes que permitam intervir na sociedade. Essa formação precisa ser efetivamente crítica e reflexiva, contribuindo para que o bibliotecário possa reavaliar permanentemente sua atuação, buscando direcioná-la rumo aos princípios de humanização e emancipação da sociedade e das pessoas em particular.

Vale ressaltar, contudo, que por se conduzir como um estudo de natureza progressiva, não houve a intenção de encerrar possíveis discussões a respeito das 
temáticas envolvidas, sendo que se procurou apenas elucidar uma posição e sua defesa quanto ao entendimento sobre a importância de se contribuir com subsídios à consolidação da competência informacional e midiática como área de importância na formação básica do bibliotecário no contexto brasileiro. Assim, espera-se que este artigo possa trazer importante colaboração para mais aprofundamentos e reflexões sobre esse tema.

Por fim, recomenda-se que a Associação Brasileira de Educação em Ciência da informação (ABECIN) se aproxime com ações efetivas em relação à temática Competência em Informação, pois, sendo ela um órgão representativo e de referência aos docentes, poderá contribuir para efetivar filosofia no âmbito da formação biblioteconômica no Brasil.

\title{
Media and Information Literacy in Librarianship Education: notes to the Brazilian Context
}

\begin{abstract}
It displays contribution the media and information literacy for teaching and learning actions that can positively influence the formation of Librarianship course students in the Brazilian context, the appropriate media and information literacy, putting them into practice through interventions teaching. The objective was to provide a reflection on the media and information literacy training librarian and all learning contexts. The research sets up a qualitative approach to literature and exploratory nature. This is a contribution of innovative and social aspects interested in adopting new postures in this teaching-learning ambience, as well as assist in the understanding of the fundamental issues related to competence in information and media, allowing its appropriation formation of Librarianship courses and promoting the deepening of reflections sometimes pointed and the need to implement it as part of the basic training of the librarian.
\end{abstract}

Keywords: Media and Information Literacy. Professional Qualification. Librarianship. Teaching. 


\section{REFERÊNCIAS}

ASSOCIATION OF COLLEGE AND RESEARCH LIBRARIES - ACRL.

Information literacy competency for higher education. Chicago: ALA, 2000.

Disponível em:

<http://www.ala.org/ala/mgrps/divs/acrl/standards/informationliteracycompetencystan dards.cfm>. Acesso em: 06 ago. 2016.

BADKE, W. Why information literacy is invisible. Communications in Information Literacy, v.4, n.2, 2010, p.129-141.

BELLUZZO, R. C. B. Competência em Informação: vivências e aprendizado. In: Regina Celia Baptista Belluzzo; Glória Georges Feres. (Org.). Competência em Informação: das reflexões às lições aprendidas. São Paulo: FEBAB, 2013, v. 1, p. 5874.

BRASIL. Ministério da Educação. Diretrizes Curriculares Nacionais dos cursos de Filosofia, História, Geografia, Serviço Social, Comunicação Social, Ciências Sociais, Letras, Biblioteconomia, Arquivologia e Museologia, 2001. Disponível em: <http://portal.mec.gov.br/cne/arquivos/pdf/CES0492.pdf.>. Acesso em: 12 set. 2016

CAVALCANTE, L. E. Políticas de formação para a competência informacional: o papel das universidades. Revista Brasileira de Biblioteconomia e Documentação: Nova Série, São Paulo, v. 2, n. 2, p. 47-62, dez. 2006.

CHAUI, M. A universidade publica sob nova perspectiva. Revista Brasileira de Educação, n.24,p.5-11, set.-dez./2003.

COONAN, E. A new curriculum for information literacy. Theoretical background Teaching learning: perceptions of information literacy. Arcadia Project, Cambridge University Library. 2011.

DELORS, J. (Org). Educação: um tesouro a descobrir. São Paulo: Cortez/Brasília: MEC: UNESCO, 1998.

DUDZIAK, E. A. Competência em Informação melhores práticas educacionais voltadas para a informationliteracy. In: Congresso Brasileiro de Biblioteconomia, Documentação e Ciência da Informação (21. : 2005 : Curitiba, PR), 2005, Curitiba, PR. CBBD 2005.. Curitiba: FEBAB, 2005. p. 1-15.

DUDZIAK, E.A. Information Literacy uma revolução silenciosa: diferentes concepções para a Competência em Informação.. In: Congresso Brasileiro de Biblioteconomia e Documentação, 20. 2002, Fortaleza. CBBD 2002: anais.. Fortaleza: Universidade Federal do Ceará, 2002. 


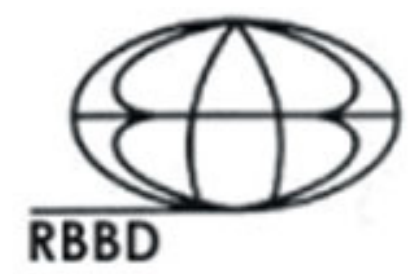

Artigos

GASQUE, K. C. G. D. Arcabouço do letramento informacional e contexto educacional. Brasília: Faculdade de Ciência da Informação/Universidade de Brasília, 2012.

LAU, J. Diretrizes sobre desenvolvimento de habilidades em informação para a aprendizagem permanente. 2007 . Disponível em:

<http://www.febab.org.br/jesus_lau_trad_livro_comp_v_f.doc $>$. Acesso em: 1 nov. 2016.

MATA, M. L.; CASARIN, H. C. S. Inserção de conteúdos de competência informacional e de formação pedagógica nos currículos dos cursos de Biblioteconomia do Brasil: uma análise por meio dos sites institucionais. In: Encontro Nacional de pesquisa em Ciência da Informação - ENANCIB, 2012, Rio de janeiro. Anais do XIII Encontro Nacional de pesquisa em Ciência da Informação - ENANCIB. Rio de Janeiro: Fiocruz, 2012. p. 1-21.

STUBBINGS, R.; FRANKLIN G. 'Does advocacy help to embed information literacy into the curriculum? A case study' Italics, n. 5, v.1, 2006. Acesso:

http://www.ics.heacademy.ac.uk/italics/vol5iss1.htm acessado em: 8 Jul 2016.

TAKAHASHI, T. Sociedade da Informação no Brasil: livro verde. Brasília: Ministério da Ciência e da Tecnologia, 2000.

UNESCO. Política de mudança e desenvolvimento no Ensino Superior. Rio de Janeiro: Garamond/Unesco, 1998.

UNESCO. Declaração mundial sobre educação superior no século XXI: visão e ação. 1998

URIBE-TIRADO, A. La Alfabetización Informacional en la Universidad. Descripción y Categorización según los Niveles de Integración de ALFIN. Caso Universidad de Antioquia. Revista Internamericana de Bibliotecología, v.33, n.1, 2010, p.31-83. http://eprints.rclis.org/14231/

VARELA, A. V.; BARBOSA, M. L. A. ; FARIAS, M. G. G. Desenvolvimento de competências informacionais, científicas e tecnológicas: responsabilidade do ensino superior com parceria entre a docência e a biblioteca. In: Regina Celia Baptista Belluzzo; Glória Georges Feres. (Org.). Competência em Informação: das reflexões às lições aprendidas. São Paulo: FEBAB, 2013, v. 1, p. 176-208.

WILSON, C. et al. Alfabetização midiática e informacional: currículo para formação de professores . Brasília: UNESCO, UFTM, 2013. 
Informações da autora

Gabriela Belmont de Farias

Professora Doutora em Ciência da Informação

Departamento de Ciências da Informação

Programa de Pós-Graduação em Ciência da Informação

Universidade Federal do Ceará

E-mail:gabibfarias@gmail.com 